\title{
TINJAUAN PERMEABILITAS DAN ABSORBSI BETON DENGAN MENGGUNAKAN BAHAN FLY ASHSEBAGAI CEMENTITIOUS
}

\author{
Review The Use of Fly-ash as a Cementitious to Concrete Absorbtion and Permeability
}

\author{
Erwin Rommel ${ }^{1}$, Yusuf wahyudi², Rozy Dharmawan ${ }^{3}$
}

${ }^{1,2}$ Jurusan Teknik Sipil Universitas Muhammadiyah Malang

J1. Raya Tlogomas 246 Malang 65144 Telp. (0341) 464318-319 Pes. 130 Fax. (0341)460435

${ }^{3}$ Alumni Jurusan Teknik Sipil Universitas Muhammadiyah Malang

Email: erwin67pro@yahoo.com

\begin{abstract}
Fly-ash material improvement efforts through the process of synthesis of silicawith the activator $\mathrm{NaOH} 5 \mathrm{M}$ solution has been done to improve the properties of reactivity. Repair of concrete permeability resistance trying to do with fly-ash as cementitious $10 \%, 20 \%, 30 \%, 40 \%$. Concrete permeabilitytesting done by making 30 specimen (20x20x12) cm. Beside that alsocarried out testing on the absorption testing by making cylinder concrete (15x30) cm as much as 30 specimen. The comparison is done as the creation of concrete using fly-ash in a conventional fly-ash on concrete. The result of absorption obtained that the use of fly ash tend to be able to reduce the absorption on the concrete, both the conventionalfly-ash or fly-ash treatment. Even the usage offly-ash above20\% is not contrastive in the absorption of concrete given the fly-ash treatment or conventional fly-ash. The capability of concrete permeability looksbetter onconcrete using fly-ash treatment comparedto conventional fly-ash.
\end{abstract}

Keywords : fly ash, permeability, absorption

\begin{abstract}
Abstrak
Upaya perbaikan material fly-ash melalui proses sintesis silika dengan aktivator $\mathrm{NaOH} 5 \mathrm{M}$ telah dilakukan guna memperbaiki sifat reaktifitasnya. Perbaikan ketahanan permeabilitas beton coba dilakukan dengan mengganti 10\%, 20\%, 30\%, 40\% berat semen dengan bahan fly-ash hasil rekayasa. Pengujian permeabilitas beton dilakukan dengan membuat 30 benda uji berukuran $(20 \times 20 \times 12) \mathrm{cm}$. Disamping itu dilakukan juga pengujian pada ketahanan absorbsi beton dengan membuat benda uji silinder diameter $15 \mathrm{~cm}$ tinggi $30 \mathrm{~cm}$ sebanyak 30 benda uji. Sebagai pembanding dilakukan pembuatan beton dengan menggunakan bahan fly-ash konvensional (tanpa perbaikan) pada campuran beton. Hasil pengujian absorbsi diperoleh bahwa penggunaan fly ashcenderung dapat mengurangi nilai absorbsi pada beton, baik pemakaian fly-ash konvensional maupun fly-ash yang telah melalui hasil rekayasa. Bahkan pemakaian fly-ash diatas $20 \%$ tidak memperlihatkan perbedaan nilai absorbsi pada beton yang diberi fly-ash hasil rekayasa maupun fly-ash konvensional. Untuk kemampuan permebilitas terlihat lebih baik pada beton yang memakai fly-ash rekayasa dibandingkan dengan fly-ash konvensional.
\end{abstract}

Kata Kunci : fly ash, permeabilitas, absorbsi

\section{PENDAHULUAN}

Beton menjadi salah satu bahan yang dibutuhkan dalam suatu pembangunan. Perkembangan ekonomi dunia yang semakin pesat saat ini membuat bangunan berbahan beton tumbuh di banyak tempat sehingga produksi beton pun meningkat jumlahnya secara signifikan. Produksi beton identik dengan merusak lingkungan semata mulai dari proses menggali batu kapur, proses pembakarannya, emisinya, dsb. Produksi semen pun dinyatakan sebagai penyumbang karbon dioksida terbesar urutan dua dunia dan menyumbang tujuh persen setelah pembangkit listrik. Oleh sebab itu, perlu senantiasa dikembangkan beton ramah lingkungan sehingga pembangunan tidak perlu berhenti demi lingkungan(Hardjito, 2010). 
Pemanfaatan bottom ash dan fly ash sebagai pembuatan beton tanpa campuran semen dan pasir juga telah di lakukan di Puslitbang Geoteknologi LIPI dengan memberikan kandungan bottom ash dan fly ash hingga $80 \%$ sehingga dapat menekan biaya produksi dan lebih tahan terhadap asam dan air laut serta memiliki beton dengan kinerja tinggi dan bobot yang ringan (Media Komunikasi dan Informasi Pembangkit Listrik Tenaga Uap, 2010).

Hasil penelitian terdahulu menunjukkan bahwa penambahan abu terbang sebagai pengganti semen pada komposisi 1:1:8 (semen:kapur:pasir)dapat meningkatkan kuat tekan dan serapan air pada mortar. Variasi penambahan abu terbang diberikan mulai 10\%,20\%,30\% dan 40\% dimana peningkatan kuat tekan terbesar terjadi pada penambahan abu terbang 30\% dengan kuat tekan mencapai 100,72 $\mathrm{kg} / \mathrm{cm}^{2}$ pada umur 56 hari. Sedangkan nilai serapan air terendah diperoleh hingga 9,31\% pada penambahan abu terbang 30\%.(Andoyo, 2006)

Bahan fly ash hasillimbah PLTU Tanjung Jati B Jepara telah dilakukan perbaikan pada sifat fisik dan kimianya dengan memakai aktivator $\mathrm{NaOH} 5 \mathrm{M}$ pada temperature $100^{\circ} \mathrm{C}$. Komposisi senyawa silika $\left(\mathrm{SiO}_{2}\right)$ bertambah hingga 37,69\% dengan bentuk fase amorf seebsar $71,31 \%$ dimana bentuk amorf dari senyawa silika tersebut merupakan indikasi tingkat reaktifitas bahan fly-ash tersebut. Uji SEM memperlihatkan permukaan butiran yang tidak beraturan pada senyawa amorf akan memudahkan pengikatan kapur bebas oleh senyawa silika dari hasil reaksi hidrasi semen. Sehingga bahan fly-ash yang telah diteratmen tersebut menjadi lebih reaktif dan memiliki sifat mengikat yang lebih kuat dan dapat digunakan sebagai bahan pengganti semen pada pembuatan beton (Erwin, Dini K dan Ansori, 2014).

Upaya memperbaiki sifat fisik dan kimia dari fly ash sebagai material pengganti sebagian semen serta pengaruh reaktifitas dari fly ash yang telah mengalami perbaikan dengan pensintesisan silika. Hasil pemeriksaan kimia menunjukkan bahwa terjadi penurunan persentase pada unsur $\mathrm{Si}$ dan $\mathrm{Al}$ akan tetapi mengalami peningkatan pada unsur $\mathrm{Fe}$. Hal tersebut juga berpengaruh terhadap kandungan senyawa utama $\mathrm{SiO}_{2}$ dan $\mathrm{Al}_{6} \mathrm{Si}_{2} \mathrm{O}_{13}$ (Mullite) yang mendominasi fly ash sebesar $77-80 \%$ mengalami penurunan setelah mengalami proses treatment. Hasil uji reaktifitas dengan menggunakan XRD didapatkan bahwa fly ash mengalami penurunan jumlah struktur amorf sebesar 3,47\% setelah mengalami proses treatment, Penurunan ini menyebabkan fly ash tidak lebih reaktif setelah melalui proses treatment dan tidak lebih baik digunakan sebagai bahan pengganti sebagian semen dalam beton secara keseluruhan.(Erwin, Dini K, dan Armand, 2014).

Tujuan penelitian ini untuk mengetahui pengaruh pemakaian fly ashyang telah melalui proses rekayasa sintesis dengan metode refluks sebagai bahan cementitious pada beton terhadap perubahan sifat permeabilitas beton dan sifat absorbsi beton.

\section{METODE PENELITIAN}

\section{Rancangan Penelitian}

Dilakukan pengujian bahan fly-ash dari limbah industri PLTU Tanjung Jati-B Jepara. Pemeriksaan fisik meliputi; berat jenis, kehalusan, serta konsistensi dimana proses tersebut dilaksanakan di Laboratorium Beton Fakultas Teknik Universitas Muhammadiyah Malang. Setelah itu dilakukan perbaikan bahan fly-ash melalui proses sintesis silika (metode refluks) dengan bahan aktivatorlarutan $\mathrm{NaOH} 5 \mathrm{M}$ pada suhu $100^{\circ}$ Cselama 24 jam.Proses rekayasa ini dilakukan dengan memakai alat refluks skala lapangan. Variasi pemakaian fly ash sebagai cementitiousmasing-masing sebanyak 0\%, 10\%, $20 \%, 30 \%, 40 \%$ dari berat semen. Pada penelitian ini dibuat 30 benda uji berukuran $(20 \times 20 \times 12) \mathrm{cm}$ untuk uji permeabilitas beton dan 30 silinder beton (30x15) cm untuk uji absorbsi beton. Jumlah benda uji setiap perlakuan terlihat pada Tabel-1.

Tabel 1. Jumlah Benda Uji

\begin{tabular}{|c|c|c|c|c|}
\hline \multirow{2}{*}{$\begin{array}{c}\text { \% fly- } \\
\text { ash }\end{array}$} & \multicolumn{2}{|c|}{$\begin{array}{c}\text { Pengujian } \\
\text { Permeabilitas }\end{array}$} & \multicolumn{2}{|c|}{$\begin{array}{c}\text { Pengujian } \\
\text { Absorbsi }\end{array}$} \\
\hline & $\begin{array}{c}\text { Treatme } \\
\text { nt }\end{array}$ & $\begin{array}{c}\text { Konvensi } \\
\text { onal }\end{array}$ & $\begin{array}{c}\text { Treatme } \\
\text { nt }\end{array}$ & $\begin{array}{c}\text { Konvensio } \\
\text { nal }\end{array}$ \\
\hline $0 \%$ & 3 & 3 & 3 & 3 \\
\hline $10 \%$ & 3 & 3 & 3 & 3 \\
\hline $20 \%$ & 3 & 3 & 3 & 3 \\
\hline $30 \%$ & 3 & 3 & 3 & 3 \\
\hline $40 \%$ & 3 & 3 & 3 & 3 \\
\hline $\begin{array}{c}\text { Jumla } \\
\text { h }\end{array}$ & \multicolumn{2}{|c|}{30} & \multicolumn{2}{|c|}{30} \\
\hline
\end{tabular}


Pengujian permeabilitas beton dilakukan berdasarkan standar DIN 1048 di Laboratorium Litbang dan Jaminan Mutu PT. Semen Gresik, sedangkan untuk pengujian absorbsi beton dilakukan di Laboratorium Beton Fakultas Teknik Univesitas Muhammadiyah Malang dengan mengacu pada SNI 03-6433-2000.

\section{Bahan Penelitian}

Bahan yang digunakan antara lain; fly ash tipeF dari PLTU Tanjung Jati B Jepara, larutan $\mathrm{NaOH}$ $5 \mathrm{M}$, semen, pasir, kerikil maks $20 \mathrm{~mm}$.

\section{Alat Penelitian}

Alat utama yang digunakan pada penelitian antara lain ; alat refluks fly ash skala lapangan (hasil modifikasi), permeability testing, oven.

\section{HASIL DAN PEMBAHASAN}

Bahan semen yang digunakan memenuhi persyaratan uji berdasarkan ASTM yang meliputi uji berat jenis, kehalusan, konsistensi, seperti terlihat pada Tabel-2.Sedangkan untuk bahan fly ash menghasilkan berat jenis yang lebih kecil dibandingkan semen. Berat jenis fly ash konvensional dan fly ash hasilperbaikan tidak berbeda jauh meskipun telah melalui proses sintesis pada fly ash, massa fly ash lebih ringan karena struktur penyusunnya. Kehalusan bahan fly-ash lebih besar bahkan melebihi 10\% yang tertahan diatas saringan No.200 dimana butiran fly-ash walaupun rentan terhadap lingkungan yang memiliki kelembabam. Bahan semen memiliki konsistensi paling rendah dibandingkan fly ash konvensional dan fly ash hasil perbaikan. Hal ini menjelaskan bahwa sifat semen dan fly-ash yang berbeda dalam hal kemampuan menyerap air. Untuk menghasilkan reaksi pasta semen dibutuhan air yang lebih banyak pada bahan fly-ash dimana nilai konsistensi lebih tinggi dari bahan semen.

\section{Semen dan Fly-ash}

Tabel 2. Hasil pengujian semen dan fly-ash

\begin{tabular}{|c|c|c|c|c|c|}
\hline \multirow{2}{*}{$\begin{array}{c}\text { Jenis } \\
\text { pemeriksaan }\end{array}$} & \multirow{2}{*}{ Standar Uji } & \multicolumn{3}{|c|}{ Hasil pengujian } & \multirow{2}{*}{ Syarat Uji } \\
\hline & & semen & fly-ash konvensional & fly-ash perbaikan & \\
\hline $\begin{array}{c}\text { Berat Jenis } \\
\left(\mathrm{gr} / \mathrm{cm}^{3}\right)\end{array}$ & $\begin{array}{c}\text { ASTM } \\
\text { C } 188144\end{array}$ & 3,16 & 2.625 & 2.60 & $3,15-3,17$ \\
\hline $\begin{array}{c}\text { Kehalusan } \\
(\%)\end{array}$ & $\begin{array}{c}\text { ASTM } \\
\text { C-134-66 }\end{array}$ & 4,9 & 10.1 & 12.84 & $<10 \%$ \\
\hline $\begin{array}{c}\text { Konsistensi } \\
(\%)\end{array}$ & $\begin{array}{c}\text { ASTM } \\
\text { C-187-71 } \\
\end{array}$ & 27 & 28 & 36 & - \\
\hline
\end{tabular}

\section{Tingkat workability}

Pengaruh kemudahan dalam pelaksanaan pengecoran betona kibat pemakaian cementitious fly-ash dapat dilihat dari hasil pengujian nilai slump pada beton segar. Pemakaian bahan fly-ash tidak terlalu berpengaruh karena nilai slump masingmasing campuran beton dengan penambahan jumlahcementitious fly-ash pada beton masih berada dalam target rencana slump yakni berkisar $10 \pm 2$ $\mathrm{cm}$. Walaupun penambahan bahan fly-ash memiliki kecendrungan turunnya nilai slump, karena bahan fly-ash lebih mudah menyerap air sehingga kebutuhan air untuk hidrasi semen menjadi berkurang dana dukan beton menjadi lebih kental atau tingkat workability menjadi berkurang. Hubungan nilai slump dengan penambahan jumlah fly-ash pada campuran beton terlihat pada Gambar-1.

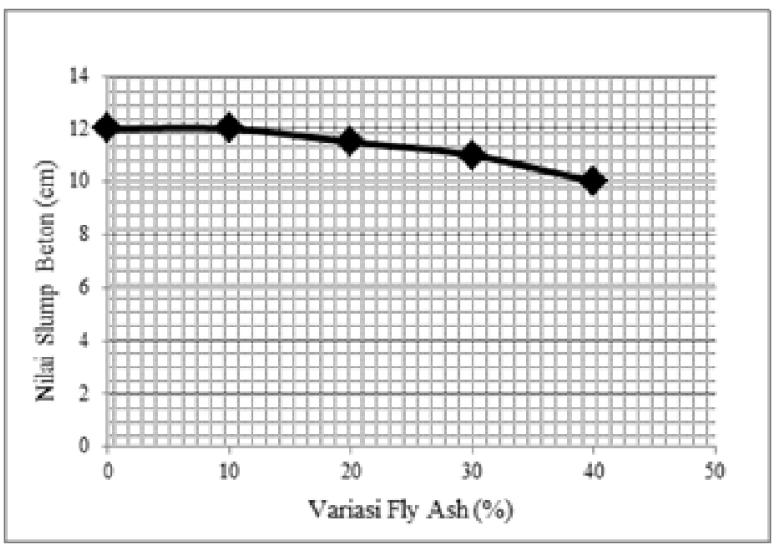

Gambar 1. Nilai Slump Beton

\section{Absorbsi Beton}

Keandalan beton terhadap lingkungan yang kedap air ditentukan oleh tingkat penyerapan air pada 
permukaan beton yang disebit absorbsi. Nilai absorbsi yang besar pada beton merupakan indikasi beton tersebut cenderung kurang awet atau memiliki durabilitas yang rendah karena beton dengan mudah menyerap air dan hal ini menyebabkan degradasi kekuatan beton. Sifat kedap air pada beton berkaitan dengan porositas dan absorbsi beton. Air dapat masuk kedalam beton tidak hanya melalui sifat porous atau rongga-rongga yang terbentuk pada beton tetapi juga melalui diffusion dan absorbtion yang semuanya tergantung pada struktur hidrasi semen.

Dari hasil pengujian absorbsi terlihat bahwa penggunaan fly ashsebagai cementitious, baik yang telah melalui proses rekayasa maupun tidak dapat memperkecil nilai absorbsi beton jika dibandingkan dengan beton konvensional. Pada pemakaian flyash sebagai cementitious sebanyak diatas $20 \%$ terlihat bahwa nilai absorbsi beton cenderung stabil dan berkurang rata-rata nilai absorbsi sebesar $45 \%$ dibandingkan dengan beton konvensional (tanpa flyash). Nilai absorbsi pada beton berkurang dari 0,93 menjadi rata-rata 0,45 .

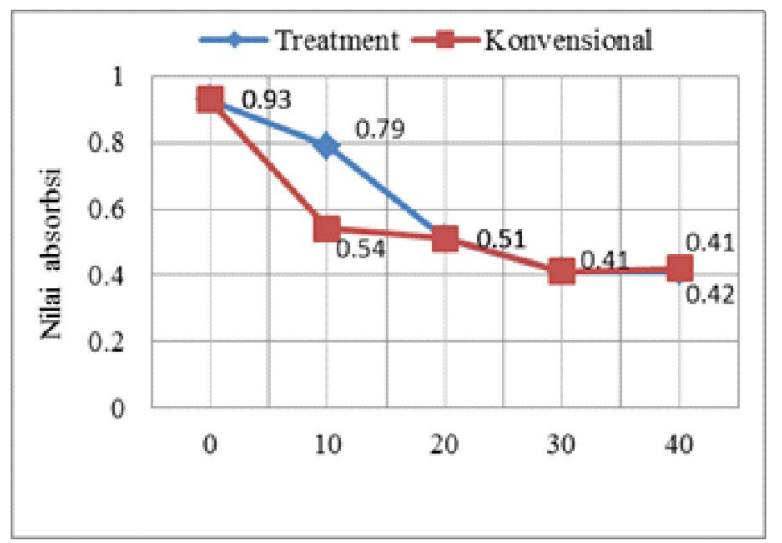

Gambar 2. Nilai absorbsi beton

Rendahnya nilai absorbsi pada beton yang memakai fly-ash sebagai cementitiouskarena memiliki pori-pori yang lebih kecil daripada semen itu sendiri serta sifat rekatan antara agregat yang semakin baik karena pengaruh unsur silika amorf yang lebih reaktif. Penyerapan terhadap air pada beton sangat tergantung pada pori-pori agregat pengisinya sehingga beton tidak mudah mereduksi air masuk pada pori-pori beton.

\section{Permeabilitas Beton}

Permeabilitas beton juga dipengaruhi oleh distribusi ukuran butiran semen atau kehalusan dari butiran semen. menggunakan butiran semen yang lebih kasar mempunyai tingkat porositas yang lebih tinggi dibandingkan dengan menggunakan ukuran butiran semen yang lebih halus. Secara umum bisa dikatakan bahwa beton yang permeabilitas lebih rendah akan memiliki kuat tekan yang lebih baik dibandingkan dengan beton dengan permeabilitas yang tinggi.

Dari hasil uji permeabilitas terlihat bahwa dengan pemakaian sebanyak $20 \%$ fly ashhasil rekayasa dapat mengurangi permeabilitas beton hingga nilai penetrasi mencapai $2,27 \mathrm{~cm}$ dari permukaan beton atau terjadi penurunan permebilitas sebesar $\quad 69,73 \%$ dibandingkan dengan beton konvensional (beton tanpa fly-ash). Nilai permeabilitas relatif kecil karena fly ash sebagai cementitious mempunyai sifat rekatan antara butiran agregat yang lebih baik karena unsur silika amorf yang lebih reaktif serta dapat memperkecil pori-pori beton itu sendiri. Karena penyerapan terhadap air sangat tergantung pada pori-pori agregat pengisinya. Hal ini akan menyebabkan semakin tertutupnya rongga-rongga pada beton, sehingga beton akan semakin sulit ditembus air.Pengunaan fly ash konvensional juga akan menurunkan nilai permeabilitas beton tetapi nilai penetrasi yang terjadi masih lebih tinggi dibandingkan dengan memakai flyash yang telah melalui proses rekayasa. Batas nilai penetrasi permeabilitas beton untuk beton kedap air adalah bila air merembes ke dalam beton kurang dari $5 \mathrm{~cm}$ (syarat standar DIN 1045).

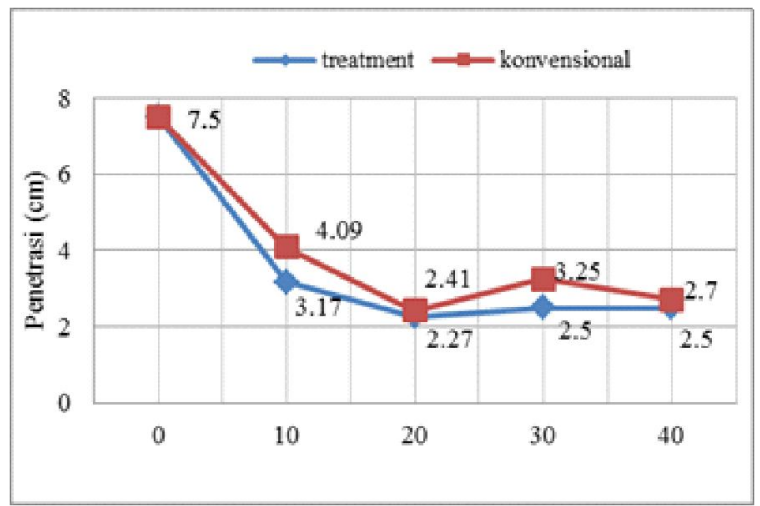

Gambar 3. Permeabilitas beton 


\section{KESIMPULAN DAN SARAN}

- Pemakaian bahanfly ashhasil proses sintesis dengan metode refluksdan fly ash konvensional sebagai cementitiousdapat mengurangi nilai absorbsi beton hingga $45 \%$ dibandingkan dengan beton konvensional (beton tanpa fly-ash).

- Pemakaian bahan fly ashhasil proses sintesis dengan metode refluks akan menghasilkan tingkat permeabilitas beton lebih baik dibandingkan beton dengan memakai fly-ash konvensional maupun beton konvensional (beton tanpa fly-ash). Tingkat permeabilitas yang diperoleh mencapai penetrasi $2,27 \mathrm{~cm}$ dan masih berada dibawah ambang batas beton kedap air yakni nilai penetrasi $5 \mathrm{~cm}$.

\section{DAFTAR PUSTAKA}

Andoyo, 2006, Pengaruh Penggunaan Abu Terbang (Fly Ash)Terhadap Kuat Tekan Dan Serapan Air Pada Mortar, skripsi, Politeknik Negeri Semarang

Badan Standardisasi Nasional, 2002, SNI 03-68632002, Metode pengambilan contoh dan pengujian abu terbang atau pozolan alam sebagai mineral pencampur dalam beton semen portland.

Erwin, R., Dini K, Arman P.P, 2014, Perbaikan Sifat Fisik Dan Reaktifitas Fly Ash Sebagai Cementitious Pada Beton, Jurnal Media Teknik Sipil, Volume XII, Nomor 2, Agustus 2014, ISSN 1693-3095.

Erwin, R., Dini K, Saiful Ansyori, 2014, Rekayasa Material Fly-Ash dengan Metode Reflux sebagai Cementitious Unggul dan Ramah Lingkungan, Konferensi Nasional Teknik Sipil (KonTeKS) ke-8, 16-17 Okt 2014, ITENAS Bandung.

Erwin, R., Yusuf W, Andi R.P, 2015, Kuat Tekan Beton dengan Pemakaian Cementitious Fly-Ash yang Telah Melalui Proses Rekayasa Material, proceeding seminar nasional ATPW 2015, ITS Surabaya

Hardjito.,D, 2010, Pembangunan Berkelanjutan, Material Beton Ramah lingkungan dan Edukasi Mahasiswa, Seminar Nasional Lingkungan Hidup, Jurusan Teknik Sipil Universitas Kristen Petra, Surabaya.
Media Komuikasi dan Informasi Pembangkit Listrik tenaga Uap, 2010, Majalah Tanjung jati, Edisi April 2010, PLTU Tanjung jati B, semarang.. 